Full length article

\title{
Influence of icosahedral short range order on diffusion in liquids: A study on $\mathrm{Al}-\mathrm{Zn}-\mathrm{Cr}$ alloys
}

\author{
Güven Kurtuldu ${ }^{\text {a, * }}$, Philippe Jarry ${ }^{\text {b }}$, Michel Rappaz ${ }^{\mathrm{a}}$ \\ ${ }^{a}$ Computational Materials Laboratory, Institute of Materials, École Polytechnique Fédérale de Lausanne, Station 12, CH-1015 Lausanne, Switzerland \\ ${ }^{\mathrm{b}}$ Constellium CRV, ZI Centr'alp, 0725 rue Aristide Bergès, BP 27, Voreppe FR-38341, France
}

\section{A R T I C L E I N F O}

\section{Article history:}

Received 28 March 2016

Received in revised form

23 May 2016

Accepted 29 May 2016

Available online 22 June 2016

Keywords:

Liquid diffusion coefficient

$\mathrm{Al}-\mathrm{Zn}-\mathrm{Cr}$

Icosahedral short range order

$\mathrm{Al}_{45} \mathrm{Cr}_{7}$

Planar front solidification

\begin{abstract}
A B S T R A C T
It has been shown recently that minute additions of $\mathrm{Cr}$ in $\mathrm{Al}-\mathrm{Zn}$ alloys refine the solidified grain structure and induce multiply-twinned grains which can only be explained if the icosahedral symmetry is considered (Kurtuldu et al., 2013). It has been suggested that $\mathrm{Cr}$ addition to Al-Zn alloys promotes the formation of icosahedral short-range order (ISRO) in the liquid, leading to the formation of icosahedral quasicrystals (iQC) acting then as a template for the nucleation of the fcc Al-phase. If ISRO exists in liquid $\mathrm{Al}-\mathrm{Zn}-\mathrm{Cr}$ alloys, this should influence diffusion of solute elements in the liquid. The present study focuses on the effect of $\mathrm{Cr}$ addition on $\mathrm{Zn}$ diffusion in liquid $\mathrm{Al}-\mathrm{Zn}-\mathrm{Cr}$ alloys. The solute diffusion coefficients of $\mathrm{Zn}$ and $\mathrm{Cr}$ in the liquid were deduced from the solute profiles in the quenched liquid ahead of a planar solidliquid interface. By comparison with the same measurement in $\mathrm{Al}-\mathrm{Zn}$ alloys, it is shown that $\mathrm{Cr}$ indeed slows down the diffusion (and mobility) of $\mathrm{Zn}$ atoms, an effect which reinforces the hypothesis of ISRO in $\mathrm{Al}-\mathrm{Zn}$ liquid induced by $\mathrm{Cr}$.
\end{abstract}

๑ 2016 Acta Materialia Inc. Published by Elsevier Ltd. All rights reserved.

\section{Introduction}

Diffusion of solute elements in liquid metallic alloys play a significant role in the formation of microstructures. Diffusion coefficients are also of theoretical interest since they are related to atomic mobilities [1]. While the atomistic structure of liquids is generally thought as totally random, Frank [2] already in 1952 suggested that atoms in metallic liquids may exhibit icosahedral short-range order (ISRO). More recently, molecular dynamics simulations [3,4] and small-angle scattering in various metallic liquids [5-8] have shown this conjecture to be real. This was also reinforced by the discovery of quasicrystals [9], for which icosahedral symmetry plays a major role. As reviewed for example in Refs. [10,11], quasicrystals (QC) with 5-fold symmetry have been observed later in many metallic systems, mainly Al-transition metal alloys.

Long before the discovery of quasicrystals, it was already known that hundreds of intermetallic crystalline compounds have complex structures containing icosahedral building blocks in their unit

\footnotetext{
* Corresponding author. Present address: Laboratory of Metal Physics and Technology, Department of Materials, ETH Zürich, $\mathrm{CH}-8093$ Zürich, Switzerland.

E-mail addresses: guven644@yahoo.com, guven.kurtuldu@mat.ethz.ch (G. Kurtuldu).
}

cell, thus demonstrating already a strong tendency for icosahedral clustering in the undercooled liquid [12]. During cooling, these crystals with large unit cells, which are now called "approximants" [13], preserve icosahedral arrangement of atoms at a local scale while establishing (unlike QC) long-range translation periodicity. Their existence in an alloy system also gives significant clues on the structure of liquids.

We have recently shown that icosahedral quasicrystals (iQC's) can also play a major role in the nucleation of the fcc Al phase during solidification of an Al-20wt\%Zn alloy [14,15]. Small additions of $\mathrm{Cr}(1000 \mathrm{ppm})$ in the liquid metal drastically decrease the size of the fcc grains and induce an abnormally high fraction of twin or near-twin grain boundaries. By careful analysis of the orientation of nearest-neighbor ( $\mathrm{nn}$ ) fcc grains, we found several multiplytwinned nn grains configurations. Their mutual orientation could be explained only if they were assumed to form on a single regular or interlocked icosahedron with the epitaxial relationship: $\langle 111\rangle_{\mathrm{fcc}} \| 3$-fold symmetry iQC axes, and $\langle 110\rangle_{\mathrm{fcc}} \perp 2$-fold symmetry iQC axes. This provided compelling evidence supporting the concept that fcc grains could nucleate from an icosahedral template, known to be present as iQC's in the supercooled liquid or as building blocks of the crystalline structure of the approximant $\mathrm{Al}_{45} \mathrm{Cr}_{7}$ phase [16-18]. Similar observations were then made for yellow gold alloys (Au-12.5 wt\%Cu-12.5 wt\%Ag) inoculated with 
very small amounts of Ir (5-200 ppm) [19]. Nucleation and growth of 10 -fold twinned dendrites on a decagonal QC have also been reported by Hornfeck et al. [20] in the Ni-Zr system.

In this QC-enhanced (or QC-mediated) nucleation mechanism of the fcc phase, ISRO in the liquid is promoted by $\mathrm{Cr}$ additions to $\mathrm{Al}-$ $\mathrm{Zn}$ alloys. But ISRO should also influence solute diffusion in the liquid, since the local covalent bonds should reduce their mobility. Accurate measurements of self-diffusion coefficient in metallic liquids are possible through the use of quasielastic neutron scattering on a picosecond time scale, which is short enough not to be disturbed by convective flow [21-24]. However, these measurements are mainly well-established in case of "incoherent scatterers" such as $\mathrm{Ni}, \mathrm{Cu}, \mathrm{Co}$ or $\mathrm{Ti}$, for which the quasielastic signal at small $q$ is dominated by the incoherent contribution. In the present study, the liquid diffusion coefficients of $\mathrm{Zn}$ and $\mathrm{Cr}$ elements in $\mathrm{Al}-$ $\mathrm{Zn}-\mathrm{Cr}$ alloys have been measured after quench from the solute concentration profiles ahead of a planar solid-liquid interface. This technique has already been used to determine diffusion coefficients of various solute elements in liquid Al [25-31]. For low solute content alloys having a narrow solidification interval, a planar front can remain stable up to a fairly high speed $v$ in a fixed thermal gradient $G$. Under such conditions, a steady-state regime is reached over fairly short distances of processing in a Bridgman furnace. The solute boundary layer ahead of the planar solid-liquid interface in a binary alloy is given in this case by the ratio $D_{\ell} / v$, thus providing a direct measurement of the solute diffusion coefficient in the liquid, $D_{\ell}$.

For systems with a high nominal solute composition (and thus a large solidification interval), the solidification speed has to be reduced accordingly in order to ensure planar front growth. Under such conditions, it is more difficult to reach steady state but the diffusion coefficient $D_{\ell}$ can still be deduced from the solute profile ahead of the planar solid-liquid interface in the transient regime [29].

\section{Experimental methods}

\subsection{General procedure}

In this study, $\mathrm{Al}-\mathrm{Cr}, \mathrm{Al}-\mathrm{Zn}$ and $\mathrm{Al}-\mathrm{Zn}-\mathrm{Cr}$ alloys were prepared in an induction furnace under $\mathrm{Ar}$ atmosphere from high purity $\mathrm{Al}$ ingots (99.99 wt\%), $\mathrm{Zn}$ rods (99.99 wt\%) and $\mathrm{Cr}$ powder (99.5 wt\%). Specimens with appropriate dimensions for Bridgman solidification (BS) experiments were extracted from the cast ingots by wire electrodischarge machining. They were then solidified in a high temperature gradient Bridgman furnace, the details of which can be found in Ref. [32]. It is just recalled that the hot stage of the BS furnace is made of an induction coil which heats up a molybdenum susceptor, itself heating by radiation the specimen contained in a ceramic crucible. The cold stage is a liquid metal cooling (LMC) bath in which the ceramic crucible is immersed.

In order to limit natural solutal convection (see below), the size of the specimen was limited by using small capillary alumina tubes with an inner diameter of $1.2 \mathrm{~mm}$ (outer diameter $2 \mathrm{~mm}$, length $140 \mathrm{~mm}$ ). Filling liquid metal into the capillary without any disruption or bubble was achieved by using an infiltration method. The alumina capillary was inserted inside an Al alloy cylinder (internal diameter $2 \mathrm{~mm}$, outer diameter $4 \mathrm{~mm}$ ). Two centering BN rings were attached to the capillary tube. The detailed sample setup configuration can be found in Ref. [33]. The whole set-up was inserted in an alumina crucible (inner diameter $4 \mathrm{~mm}$, outer diameter $7 \mathrm{~mm}$ and length $500 \mathrm{~mm}$ ) and mounted in the BS furnace. After the sample was placed inside the furnace, the chamber and crucible were evacuated and purged with Ar gas three times. The susceptor was then heated up to $900{ }^{\circ} \mathrm{C}$ at a controlled rate and the sample was maintained at this temperature for $15 \mathrm{~min}$. The molten alloy, which then overflows over the mouth of the capillary, was then pushed inside by applying an Ar pressure of $300 \mathrm{kPa}$ in the crucible. Once the capillary tube was infiltrated by the alloy, the crucible was lowered at $2 \mathrm{~mm} / \mathrm{min}$ until it was immersed $20 \mathrm{~mm}$ into the liquid metal cooling bath. The whole system was equilibrated for $2 \mathrm{~h}$ and directional solidification was then performed at a sufficiently low velocity that ensured planar front growth.

The temperature during the whole experiment was controlled by a thermocouple inserted in an alumina capillary and placed at the center of the sample. Between the solidus and liquidus temperatures of Al-20 wt\% $\mathrm{Zn}\left(T_{\text {Sol }}=585^{\circ} \mathrm{C}, T_{\text {Liq }}=626{ }^{\circ} \mathrm{C}\right)$, a thermal gradient $G \approx 100 \mathrm{~K} / \mathrm{cm}$ was measured. Based on this value, the pulling speed $v_{p}$ ensuring steady-state planar front growth was estimated to be $0.8 \mu \mathrm{m} / \mathrm{s}$ according to the constitutional undercooling criterion [34]:

$v_{p}<v_{c}=\frac{G D_{\ell}}{\Delta T_{0}}$

where $v_{c}$ is the critical velocity above which instabilities of the solid-liquid front develop, $\Delta T_{0}=\left(T_{\text {Liq }}-T_{\text {Sol }}\right)$ is the solidification interval of the alloy and $D_{\ell}$ is the solute diffusion coefficient in the liquid (estimated to be on the order of $3 \times 10^{-9} \mathrm{~m}^{2} / \mathrm{s}$ prior to the present measurements).

\subsection{Diffusion coefficient measurement}

The diffusion coefficient of $\mathrm{Cr}$ and $\mathrm{Zn}$ in liquid binary ( $\mathrm{Al}-\mathrm{Cr}$ and $\mathrm{Al}-\mathrm{Zn})$ and ternary (Al-Zn-Cr) alloys have been measured from the corresponding solute composition profile in the liquid, either during steady state or during the transient. At the end of solidification at constant pulling speed, a fast quench froze the solute profiles and ensured that the interface motion during quenching is negligible compared to the thickness of the solute boundary layer. Composition profiles in the solid and quenched liquid were measured by an electron probe microanalyzer (EPMA) and Energy Dispersive X-ray (EDX) analysis, as a function of the distance to the quenched interface. Since the quenched microstructure is composed of fine eutectic and dendrites, the composition measurements were averaged on $500 \mu \mathrm{m}$ line scans parallel to the quenched interface. While 10 points were measured in the solid on a line scan for each distance from the interface, each line scan value in the quenched liquid was an average over 30 points. The standard deviations of $\mathrm{Zn}$ and $\mathrm{Cr}$ compositions for a line scan in the solid are about $0.15 \mathrm{wt} \%$ and $0.02 \mathrm{wt} \%$, respectively. Although more points were used in the quenched liquid, the corresponding solute compositions showed larger deviations due to the formation of the microstructure during quenching. The standard deviation of $\mathrm{Zn}$ and $\mathrm{Cr}$ compositions for a line scan in the liquid are about $6 \mathrm{wt} \%$ and $0.02 \mathrm{wt} \%$, respectively.

\subsection{Effect of convection}

As mentioned earlier, avoiding convection in the liquid is crucial in the determination of liquid diffusion coefficients. In LMC configuration where gravity is opposed to the vertical thermal gradient, the gradient of liquid density ahead of a planar front in $\mathrm{Al}-$ $\mathrm{Zn}$ specimens is parallel to gravity, i.e., opposed to the thermal gradient. Indeed, besides thermal expansion of the liquid (cold and denser liquid is below), rejected zinc is also heavier than aluminum $\left(k_{Z n}>1\right.$, where $k_{Z n}$ is the partition coefficient of $\left.\mathrm{Zn}\right)$. In $\mathrm{Al}-\mathrm{Cr}$ or Al$\mathrm{Zn}-\mathrm{Cr}$, the effect of chromium can be neglected although this solute element is depleted in the liquid [33] $\left(k_{C r}>1\right)$ and heavier than aluminum. Indeed, the $\mathrm{Cr}$ composition of the specimens is very low 
$(\sim 0.1 \mathrm{wt} \%)$ and the solidification interval of the binary Al-Cr system is very small [35].

Nevertheless, fluid flow can still occur if there is a small horizontal component of the thermal gradient. Such can be the case in our BS setup, since the sample is heated radially by the Mo susceptor with the low-thermal conductivity ceramic crucible in between [36]. This is particularly the case if the solid-liquid front is not precisely located in the middle of the adiabatic zone between the hot and cold stages. Fig. 1 shows the quenched solid-liquid interface of an $\mathrm{Al}-20 \mathrm{wt} \% \mathrm{Zn}$ alloy directionally solidified in a $4 \mathrm{~mm}$ inner diameter crucible with $G=100 \mathrm{~K} / \mathrm{cm}$ and $v_{p}=0.8 \mu \mathrm{m} / \mathrm{s}$. The solid-liquid front is indeed stable under such growth conditions, but definitely curved. The convex shape of the solid phase, with the presence of quenched liquid near the surface of the crucible, indicates that solutal convection of zinc is from the center to the periphery of the specimen, i.e., of a solidus isotherm that is also convex (i.e., the radial component of the thermal gradient, $G_{r}$, is positive). In order to limit the influence of convection on the measurement of diffusion coefficients [29,37], the diameter of the specimens was reduced from $4 \mathrm{~mm}$ (Fig. 1) to $1.2 \mathrm{~mm}$.

\section{Modeling planar front solidification}

Smith et al. [38] studied the initial transient of planar front growth and based on a few assumptions, they developed analytical solutions for the evolution of the solute profiles in the solid and liquid phases. For more realistic situations, some of these assumptions need to be relaxed and this then requires to use numerical methods. In the present case, the 1-dimensional finite differences model developed by Valloton et al. [39] has been used. This model first considers a variable velocity $v^{*}$ of the solid-liquid front during the initial transient. This velocity increases from zero at the start of solidification, when the interface is at the liquidus temperature of the alloy, to the pulling speed $v_{p}$, when steady state is reached and the temperature of the interface is that of the solidus. Secondly, the model also accounts for the liquid velocity induced by solidification shrinkage, since the densities of the solid and liquid are not equal. The fluid velocity, $v_{\ell}$, at the interface position is given by $-\beta_{s l} v^{*}$ where $\beta_{s l}=\left(\rho_{s}-\rho_{\ell}\right) / \rho_{\ell}$ is the shrinkage factor, $\rho_{s}$ and $\rho_{\ell}$ being the solid and liquid densities, respectively.

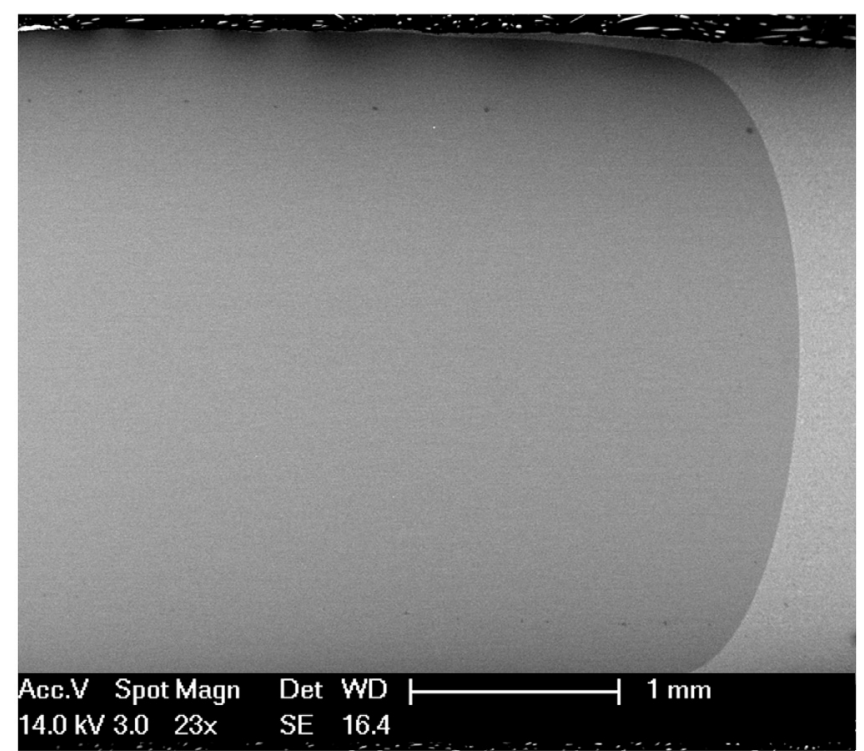

Fig. 1. A quenched solid-liquid interface of Al-20 wt $\% Z n$ growing at $G=100 \mathrm{~K} / \mathrm{cm}$, $v_{p}=0.8 \mu \mathrm{m} / \mathrm{s}$ in an alumina tube with $4 \mathrm{~mm}$ inner diameter.
Please note that $\beta_{s l}$ depends on the $\mathrm{Zn}$ composition: at low $\mathrm{Zn}$ composition, it is positive (the solid is denser than the liquid), but for higher composition it becomes negative due to the leaner $\mathrm{Zn}$ content of the solid. Although the liquid density itself is a function of the $\mathrm{Zn}$ composition (in particular within the diffusion layer), it was assumed constant and equal to that of the interface. Thirdly, the solidus and liquidus lines of the Al- $\mathrm{Zn}$ phase diagram being curved, tabulated values calculated with Thermocalc have been used instead of the assumption of a linear phase diagram (and constant partition coefficient).

The main aspects of the model are shown schematically in Fig. 2 for a binary system. A sample of initial composition $C_{0}$ is pulled with a velocity $-v_{p}\left(v_{p}<v_{c}\right)$ through an imposed thermal gradient $G$. Two reference frames are considered: the $x$-axis is attached to the sample while the $z$-axis is attached to the solid-liquid interface and moves with the velocity $v^{*}$. The assumptions of the model are as follows:

- The problem is one dimensional.

- The temperature at any given point and time within the specimen is given by:

$T(x, t)=T_{\text {Liq }}\left(C_{0}\right)+G\left(x-v_{p} t\right)$

- The composition of the liquid at the interface is given by the phase diagram:

$C_{\ell}^{*}=C_{L i q}\left(T^{*}\right)$

where $C_{L i q}(T)$ is the equation of the liquidus line and $T^{*}$ is the interfacial temperature given by Eq. (2) taken at the actual position $x^{*}$.

- The densities of the liquid and solid are constant, but not equal.

- Solid state diffusion is neglected, i.e., $D_{s}=0$. The composition profile in the solid is then "frozen" and corresponds to the interfacial liquid composition of the solute element multiplied by its partition coefficient $k$. The diffusion calculation can thus be performed in the liquid domain only.

- The diffusion coefficient $D_{\ell}$ in the liquid domain for a given nominal composition is uniform and constant.

- The length of the liquid domain in which the calculation is performed remains equal to $L$ and thus the specimen is assumed to be much longer than the distance to establish steady state and the boundary layer thickness in the liquid (semi-infinite approximation). The final transient is therefore not considered.

Under such assumptions, the diffusion equation in the liquid phase solved in the moving reference frame is given by:

$-D_{\ell} \frac{\partial^{2} C_{\ell}}{\partial z^{2}}+v_{\ell}^{\prime} \frac{\partial C_{\ell}}{\partial z}+\frac{\partial C_{\ell}}{\partial t}=0$

where $C_{\ell}$ is the solute composition in the liquid and $v_{\ell}^{\prime}$ is the apparent liquid velocity in the moving frame, which can be related to $v^{*}$ with the following relationship:

$v_{\ell}^{\prime}=-\left(1+\beta_{S \ell}\right) v^{*}$

The liquid domain of length $L$ is subdivided into $N$ grid points (see Fig. 2). The composition at the interface, $C_{\ell}^{*}$, is used as a Dirichlet condition at the first nodal point (position $z_{1}=0$ ) while a homogeneous Neumann condition is set at the last one (position $z_{N}=L$ ). The diffusion equation is expressed using a finite differences method, an implicit scheme to avoid any Fourier criterion and 


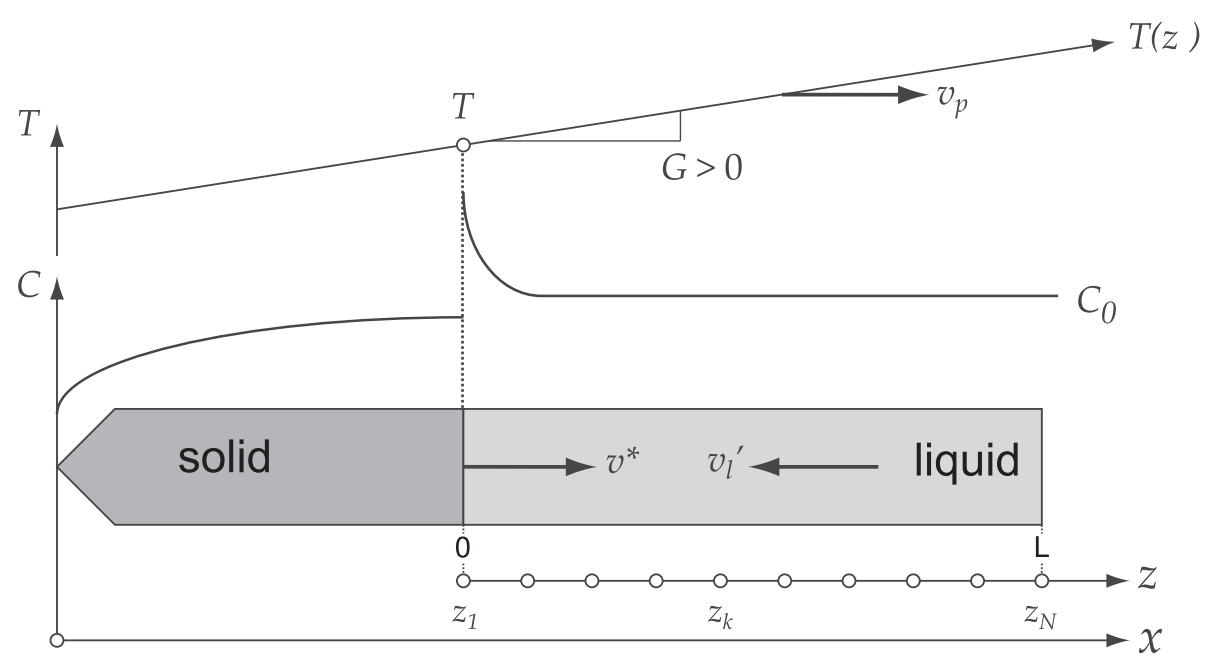

Fig. 2. Schematic diagram of the numerical model used for the segregation calculation (see text) [39].

a tridiagonal matrix algorithm to obtain the nodal compositions.

The interface velocity is updated at each time step using the solutal balance equation:

$\left.\rho_{\ell} D_{\ell} \frac{\partial C_{\ell}}{\partial z}\right|^{*}=-\rho_{S} v^{*} C_{\ell}^{*}(1-k)$

The numerical model described above was also applied to the $\mathrm{Al}-\mathrm{Zn}-\mathrm{Cr}$ ternary system by assuming that there is no interaction between the solute elements (this hypothesis is discussed later in the paper). Therefore, the diffusion equation (Eq. (4)) can be solved independently for each solute element (diffusion coefficients of solute elements in ternary alloys are labelled with a " , " upper index to distinguish them from the corresponding values measured in the binary alloys).

\section{Results}

\subsection{Cr diffusion in liquid Al-Cr alloy}

Using the same BS experimental procedure for an $\mathrm{Al}-0.08 \mathrm{wt} \% \mathrm{Cr}$ alloy, we have been able recently to end a controversy about the nature of the invariant between liquid, $\mathrm{Al}$ and $\mathrm{Al}_{45} \mathrm{Cr}_{7}$ [33]. Chromium was shown to be depleted in the liquid ahead of the quenched planar solid-liquid interface, thus proving that the invariant reaction on the $\mathrm{Al}$-rich side of the $\mathrm{Al}-\mathrm{Cr}$ phase diagram is peritectic. Measuring the slope of the solute profile in the quenched liquid after steady state growth was reached, a value $D_{\ell, \mathrm{Cr}}=2.4 \times 10^{-9} \mathrm{~m}^{2} / \mathrm{s}$ was deduced for the diffusion coefficient of $\mathrm{Cr}$ in liquid $\mathrm{Al}\left(T^{*}=660.6^{\circ} \mathrm{C}\right)$. This value is in close agreement with the measurement of Shibata et al. [27], i.e., $2.28 \times 10^{-9} \mathrm{~m}^{2} / \mathrm{s}$. The partition coefficient measured from the composition jump at the quenched interface, $k_{C r}=1.71$, is also in good agreement with the phase diagram of Murray $\left(k_{C r}=1.75\right)$ [35].

\subsection{Zn diffusion in liquid Al-Zn alloys}

The diffusion coefficient of $\mathrm{Zn}$ in liquid Al-Zn alloy was measured for various $\mathrm{Zn}$ initial compositions: 6.5, 12.8 and $18.4 \mathrm{wt}$ $\%$. Fig. 3(a) shows the quenched solid-liquid interface in a longitudinal section of an Al-6.5 wt\%Zn sample after 80,000 s of growth. It is planar over the entire cross section and no radial segregation is apparent in the sample. This demonstrates that solute transport was controlled mainly by diffusion in the small capillaries, with no
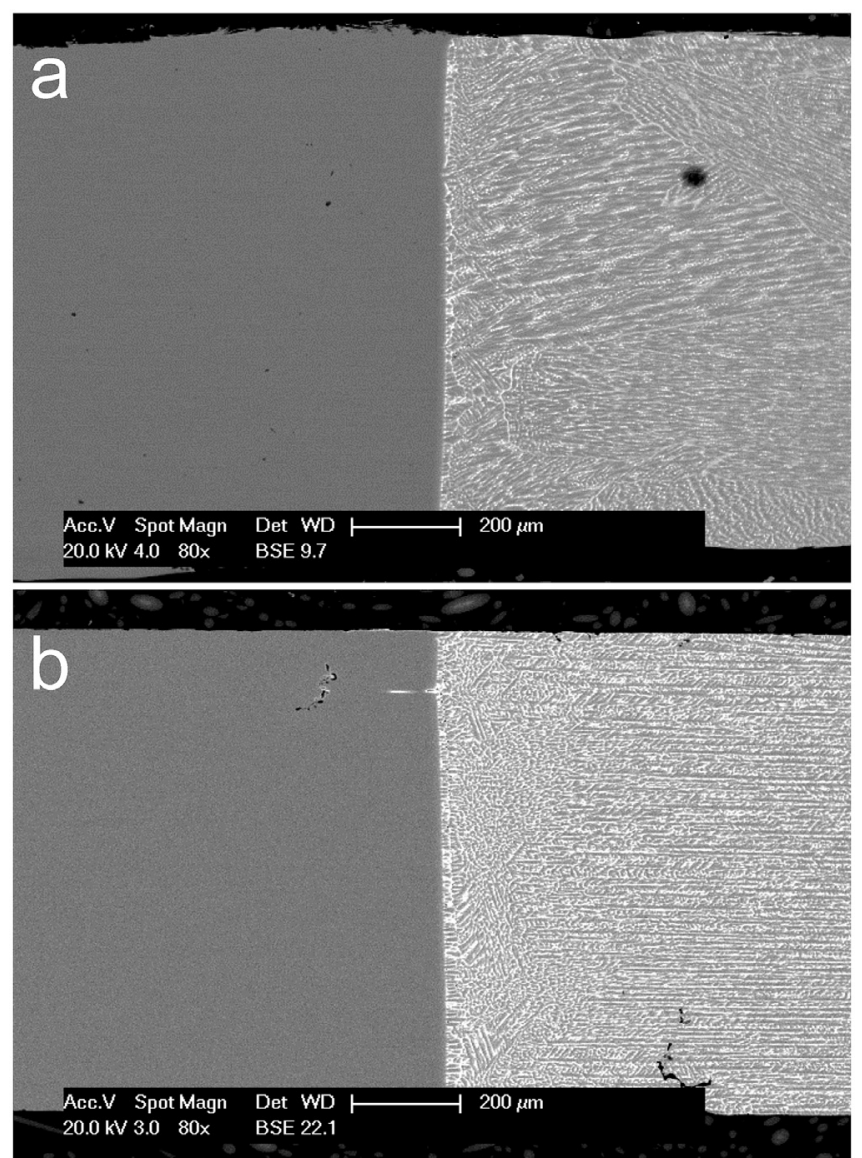

Fig. 3. Planar solid-liquid interfaces in the longitudinal section of (a) an Al-6.5 wt\%Zn alloy $\left(v_{p}=0.75 \mu \mathrm{m} / \mathrm{s}, G=100 \mathrm{~K} / \mathrm{cm}\right.$ and $\left.t=80,000 \mathrm{~s}\right)$ and (b) an Al-17.6 wt\%Zn-0.1 wt\% Cr alloy $\left(v_{p}=0.75 \mu \mathrm{m} / \mathrm{s}, G=100 \mathrm{~K} / \mathrm{cm}, t=25,740 \mathrm{~s}\right)$ in a $1.2 \mathrm{~mm}$ diameter tube.

visible effect of a radial component of $G$ and induced convection (except that associated with shrinkage). The quenched liquid shows a fine dendritic structure. Dendrites initiated by planar front instabilities during quenching grow over about $10-50 \mu \mathrm{m}$ before being stopped by equiaxed grains nucleated in the liquid. Beyond the equiaxed zone, the quenched liquid exhibits longer and larger 
grains with nearly random orientation. Although this specific quenched grain structure is probably linked with the supersaturation ahead of the planar front at the time of the quench, it was not further investigated. The $\mathrm{Zn}$ compositions in the solid and liquid close to the interface show that the motion of the flat interface during quenching was negligible.

The Al-Zn system having a much larger solidification interval than that of Al-Cr, the critical pulling speed $v_{c}$ is lower (Eq. (1)) and the transient before reaching steady state extends over longer distances for this alloy. While steady could be reached for the samples with 6.5 and $18.4 \mathrm{wt} \% \mathrm{Zn}$ compositions, the growth of the Al-12.8 wt\%Zn sample was interrupted during the initial transient at a value $C_{s}^{*} / C_{0}=0.88$ (instead of 1 for steady state). The solidification shrinkage value, $\beta_{s \ell}$, calculated with the interfacial compositions are $0.014,-0.02$ and -0.06 for $\mathrm{Al}-6.5 \mathrm{wt} \% \mathrm{Zn}, \mathrm{Al}-12.8 \mathrm{wt} \%$ $\mathrm{Zn}$ and $\mathrm{Al}-18.4 \mathrm{wt} \% \mathrm{Zn}$, respectively.

The liquid diffusion coefficient of $\mathrm{Zn}$ in these three alloys was deduced by a least-squares curve fit based on the compositions $C_{\ell}(z)$ measured in the quenched liquid (Section 2) and the numerical solution obtained with the model described in Section 3. The compositions measured over the first millimeter from the interface were weighted by a factor 3 compared to those of the remaining profile.

The measured composition profiles in the quenched liquid and the best fit obtained from the numerical model for the three alloys are shown in Fig. 4. This procedure allowed to deduce the liquid $\mathrm{Zn}$ diffusion coefficient, $D_{\ell, Z n}$, as well as the partition coefficient, $k_{Z n}$, listed in Table 1 . The values of $D_{\ell}$ reported in this table were finally assigned the temperature $T^{*}$ of the solid-liquid interface at the time of the quench, using the interfacial compositions and the Al-Zn phase diagram [40].

The values of the $\mathrm{Zn}$ diffusion coefficients in liquid $\mathrm{Al}$ listed in Table $1, D_{\ell, Z n}(T)$, can be compared with two previous experimental studies found in the literature. The first measurements of Kopach et al. [41] to determine the temperature dependence of $\mathrm{Zn}$ diffusion in liquid $\mathrm{Al}$ were performed using the liquid capillary method with 1.2-1.6 $\mathrm{mm}$ inner diameter tubes. The data points of these authors (using a logarithmic scale) are reported with open squares in Fig. 5 as a function of the inverse of the temperature in Kelvin, together with those of the present study (filled circles). Sato et al. [25] used planar front solidification experiments to solidify $\mathrm{Al}-0.08 \mathrm{wt} \% \mathrm{Zn}$ specimens but with fairly large dimensions $(5 \mathrm{~mm} \times 3 \mathrm{~mm} \times 220 \mathrm{~mm})$. Their measured value, $D_{\ell}=4.67$ $\times 10^{-9} \mathrm{~m}^{2} / \mathrm{s}$, is shown in Fig. 5 by an open triangle.

As can be seen in Fig. 5, the measured diffusion coefficients of $\mathrm{Zn}$ in liquid Al-Zn alloy are in good agreement with those of the literature. However, while making this comparison, it should be kept in mind that the concentration dependence of $D_{\ell}$ was neglected in our study, while the literature values were all measured for more dilute solutions. Neglecting the influence of composition and diffusion being a thermally-activated process, an Arrhenius relationship:

$D_{\ell}=D_{\ell, 0} \exp \left(\frac{-E_{a}}{R T}\right)$

was used to fit the present values and those of the literature (line drawn in Fig. 5). The pre-exponential factor $D_{\ell, 0}=1.62 \times 10^{-6} \mathrm{~m}^{2} / \mathrm{s}$ and the activation energy $E_{a}=44.7 \mathrm{~kJ} / \mathrm{mol}$ are quite different from the values predicted by Du et al. [42].

\section{3. $\mathrm{Cr}$ and $\mathrm{Zn}$ diffusion in liquid $\mathrm{Al}-\mathrm{Zn}-\mathrm{Cr}$ alloys}

In order to see the influence of $\mathrm{Cr}$ additions on diffusion in $\mathrm{Al}-\mathrm{Zn}$ alloys, planar front growth experiments were performed on the ternary system with various $\mathrm{Cr}$ and $\mathrm{Zn}$ compositions. Fig. 3(b) shows the quenched solid-liquid interface of an Al-17.6 wt\%Zn$0.1 \mathrm{wt} \% \mathrm{Cr}$ alloy. As for Fig. 3(a) without $\mathrm{Cr}$, fine dendrites grow epitaxially from the interface over a distance of about $50 \mu \mathrm{m}$ before being stopped by equiaxed grains. However, beyond this equiaxed region, columnar dendrites very well aligned with the capillary axis (i.e., perpendicular to the planar solid-liquid interface) are clearly visible.

The composition profiles of an Al-17.6 wt\%Zn- $0.1 \mathrm{wt} \% \mathrm{Cr}$ alloy shown in Fig. 6 demonstrates that while $\mathrm{Zn}$ is rejected into the liquid, $\mathrm{Cr}$ is depleted of the interface. After $25,740 \mathrm{~s}$, solidification was interrupted during the initial transient regime with a ratio $C_{s, Z n}^{*} / C_{0, Z n}=0.94$. The slightly increasing $\mathrm{Zn}$ composition of the frozen solid also indicates that steady state was not reached. If the interactions between $\mathrm{Cr}$ and $\mathrm{Zn}$ solute elements is neglected (no cross-diffusion), the diffusion coefficients of $\mathrm{Cr}$ and $\mathrm{Zn}$ in liquid $\mathrm{Al}-$ $\mathrm{Zn}-\mathrm{Cr}$ can be determined independently using the measured profiles and the model for binary alloys described in Section 3. The influence of $\mathrm{Cr}$ on the temperature of the interface during the transient, $T^{*}$, as well as on solidification shrinkage $\left(\beta_{s \ell}=-0.06\right.$ in this case) was neglected since the $\mathrm{Cr}$ composition of the alloy is very low and its solidification interval very narrow. The values of the two diffusion coefficients deduced for this alloy, $D_{\ell, Z n}^{\prime}$ and $D_{\ell, C r}^{\prime}$, are listed in Table 1. While the calculated profiles in the quenched liquid are in good agreement with the measured values, the experimental $\mathrm{Cr}$ profile in the solid near the interface does not match very well the calculated one (Fig. 6). This is probably due to the varying $\mathrm{Cr}$ partition coefficient, $k_{C r}$, during solidification. Indeed, while the partition coefficient for $\mathrm{Zn}, k_{\mathrm{Zn}}(\mathrm{T})$, was variable during the calculations and taken from the tabulated binary phase diagram, that of $\mathrm{Cr}$ was fixed $\left(k_{\mathrm{Cr}}=2.85\right)$.

The temperature of the solid-liquid interface at the time of the quench was determined from the ternary $\mathrm{Al}-\mathrm{Zn}-\mathrm{Cr}$ phase diagram calculated by ThermoCalc (Fig. 7(a)) using the SSOL2 database and the solute compositions measured in the solid at the interface. The deduced value of $T^{*}, 602{ }^{\circ} \mathrm{C}$, corresponds to an isothermal section for which the solute compositions in the liquid at the interface indicate the formation of the $\mathrm{Al}_{45} \mathrm{Cr}_{7}$ intermetallic phase ahead of the $\alpha$-planar interface. In order to determine the undercooled zone ahead of the quenched interface, the liquidus temperatures of $\mathrm{Al}_{45} \mathrm{Cr}_{7}$ and $\alpha$-Al phases were calculated using ThermoCalc and the solute compositions measured in the quenched liquid. Using fourth-order polynomial fits, the two liquidus lines are drawn in Fig. 8 together with the temperature profile imposed by the furnace. This profile was determined from the interface temperature and the thermal gradient. As can be seen, the $\alpha$-Al liquidus line is always below the actual temperature in the liquid, as expected for planar front growth. However, although intermetallic phases could not be observed in the quenched liquid by SEM, the liquid is undercooled over a distance of $4 \mathrm{~mm}$ ahead of the interface with respect to the $\mathrm{Al}_{45} \mathrm{Cr}_{7}$ liquidus. The maximum undercooling reaches $\sim 25^{\circ} \mathrm{C}$ at the interface. Although DTA results of Al-Cr alloys showed that high undercooling $\left(40{ }^{\circ} \mathrm{C}\right.$ for $\mathrm{Al}-2 \mathrm{wt} . \% \mathrm{Cr}$ alloy at $10 \mathrm{~K} / \mathrm{min}$ cooling rate) is required for the nucleation of $\mathrm{Al}_{45} \mathrm{Cr}_{7}$ [43], the deduced solute diffusion coefficients can be affected by the formation of $\mathrm{Al}_{45} \mathrm{Cr}_{7}$ intermetallic phase. Please note that the tie line deduced from the solid/liquid interfacial compositions (or the partition coefficients for $\mathrm{Zn}$ and $\mathrm{Cr}$ listed in Table 1) does not agree with the calculated isothermal section shown in Fig. 7(a). This raises the question of the validity of the phase diagram data and/or of the assumption of local interfacial equilibrium.

Another alloy of lower composition, Al-5.1 wt\%Zn-0.065 wt\%Cr, was solidified with a higher pulling speed $\left(v_{p}=1.56 \mu \mathrm{m} / \mathrm{s}\right)$ since its solidification interval $\Delta T_{0}$ is reduced (Eq. (1)). After $26,400 \mathrm{~s}$, solidification was interrupted during the steady-state regime. The 

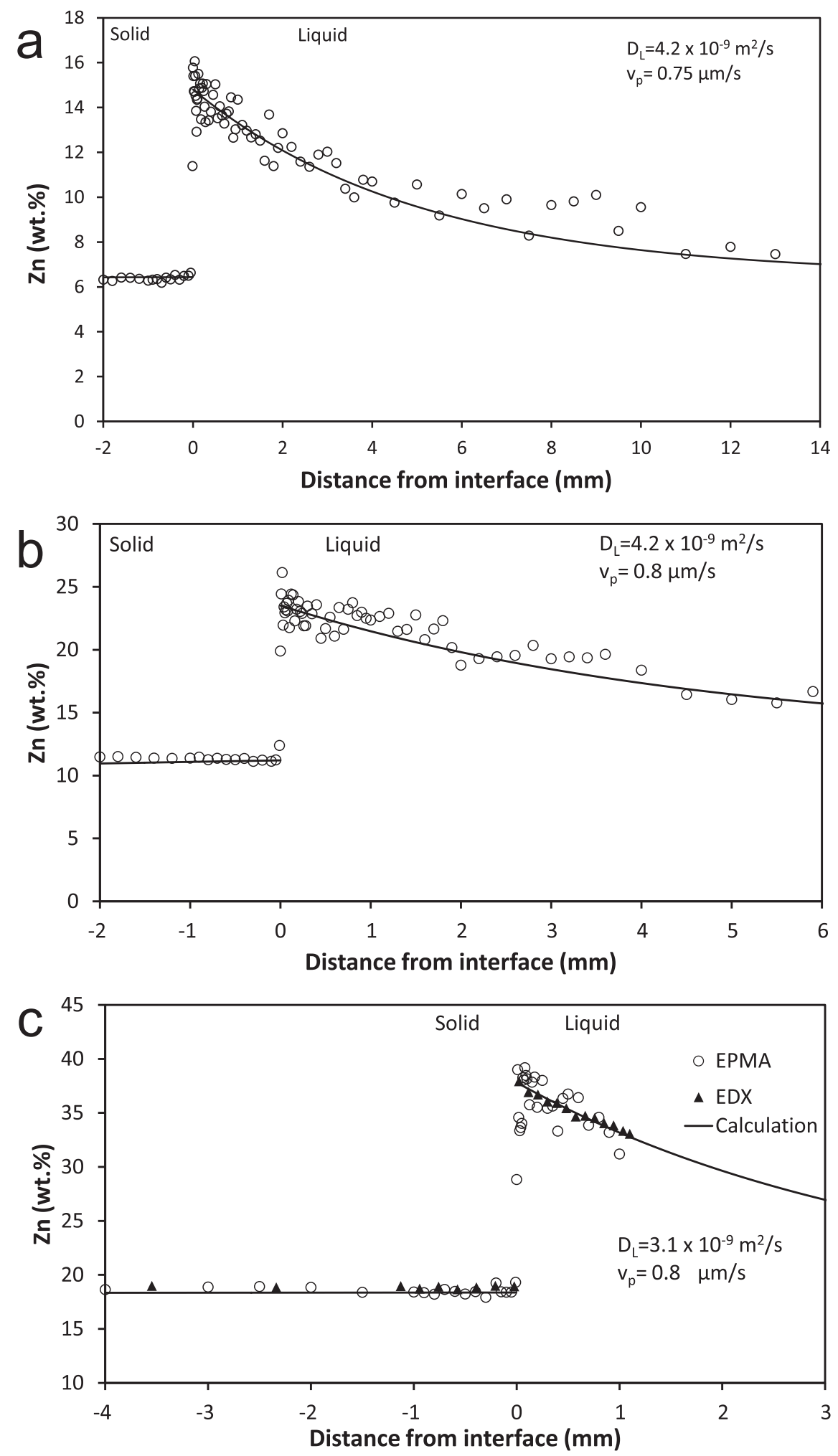

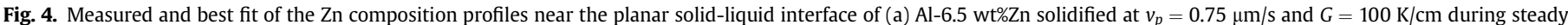

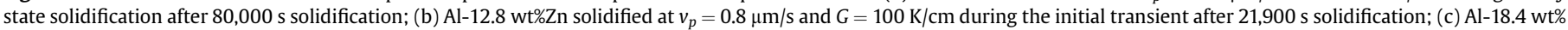

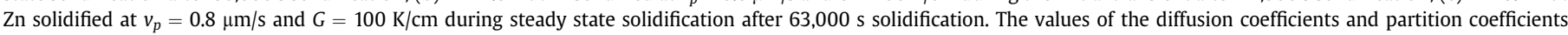
deduced from the best fits are listed in Table 1 .

ratio of the $\mathrm{Zn}$ composition in the solid at the interface and the nominal $\mathrm{Zn}$ composition, $C_{s, Z n}^{*} / C_{0, Z n} \approx 1$ demonstrates that steadystate had been reached at the time of the quench (Fig. 9). Steady state is confirmed by the flat profiles measured in the solid. Using the same procedure as before (but with $\beta_{s \ell}=0.06$ for this $\mathrm{Zn}$ composition), the diffusion coefficients listed in Table 1 were 
Table 1

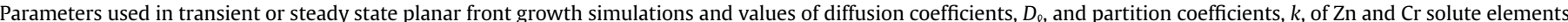

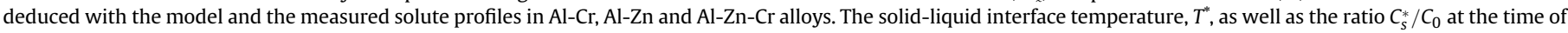
the quench are also listed.

\begin{tabular}{|c|c|c|c|c|c|c|c|}
\hline $\begin{array}{l}\text { Alloy } \\
\text { (wt\%) }\end{array}$ & $\begin{array}{l}v_{p} \\
(\mu \mathrm{m} / \mathrm{s})\end{array}$ & $\begin{array}{l}\text { Solidification } \\
\text { time }(s)\end{array}$ & $L_{\text {Solid }}(\mathrm{mm})$ & $\begin{array}{l}C_{s}^{*} / C_{0} \\
(\mathrm{wt} \% / \mathrm{wt} \%)\end{array}$ & $\begin{array}{l}k \\
\text { (wt\%/wt\%) }\end{array}$ & $\begin{array}{l}T^{*} \\
\left({ }^{\circ} \mathrm{C}\right)\end{array}$ & $\begin{array}{l}D_{\ell} \\
\left(\times 10^{-9} \mathrm{~m}^{2} / \mathrm{s}\right)\end{array}$ \\
\hline $\mathrm{Al}-0.08 \% \mathrm{Cr}$ & 5 & 3,600 & $\approx 18$ & $\approx 1$ & 1.71 & 660.6 & 2.4 \\
\hline Al-6.5\%Zn & 0.75 & 80,000 & $\approx 57$ & $\approx 1$ & 0.44 & 635 & 4.2 \\
\hline $\mathrm{Al}-12.8 \% \mathrm{Zn}$ & 0.8 & 21,900 & $\approx 16$ & $\approx 0.88$ & 0.47 & 619 & 4.2 \\
\hline $\mathrm{Al}-18.4 \% \mathrm{Zn}$ & 0.8 & 63,000 & $\approx 47$ & $\approx 1$ & 0.49 & 592 & 3.1 \\
\hline \multirow[t]{2}{*}{ Al-5.1\%Zn-0.065\%Cr } & 1.56 & 26,400 & $\approx 40$ & $\approx 1$ & $k_{Z n}=0.45$ & 642 & $D_{\ell, Z n}^{\prime}=3.3$ \\
\hline & & & & & $k_{C r}=1.75$ & & $D_{\ell, C r}^{\prime}=1.7$ \\
\hline \multirow[t]{2}{*}{ Al-17.6\%Zn-0.1\%Cr } & 0.75 & 25,740 & $\approx 16$ & For $\mathrm{Zn}$ & $k_{Z n}=0.47$ & 602 & $D_{\ell, Z n}^{\prime}=2.6$ \\
\hline & & & & $\approx 0.94$ & $k_{C r}=2.85$ & & $D_{\ell, C r}^{\prime}=1.8$ \\
\hline
\end{tabular}

deduced from these profiles with the numerical model.

Please note that the low nominal composition of this alloy prevents the potential formation of the intermetallic phase ahead

of the solid-liquid interface, as shown in the isothermal section of the ternary phase diagram (Fig. 7(b)) performed at the steady-state interfacial temperature $\left(T^{*}=642{ }^{\circ} \mathrm{C}\right)$. As for the previous $\mathrm{Al}-\mathrm{Zn}-\mathrm{Cr}$

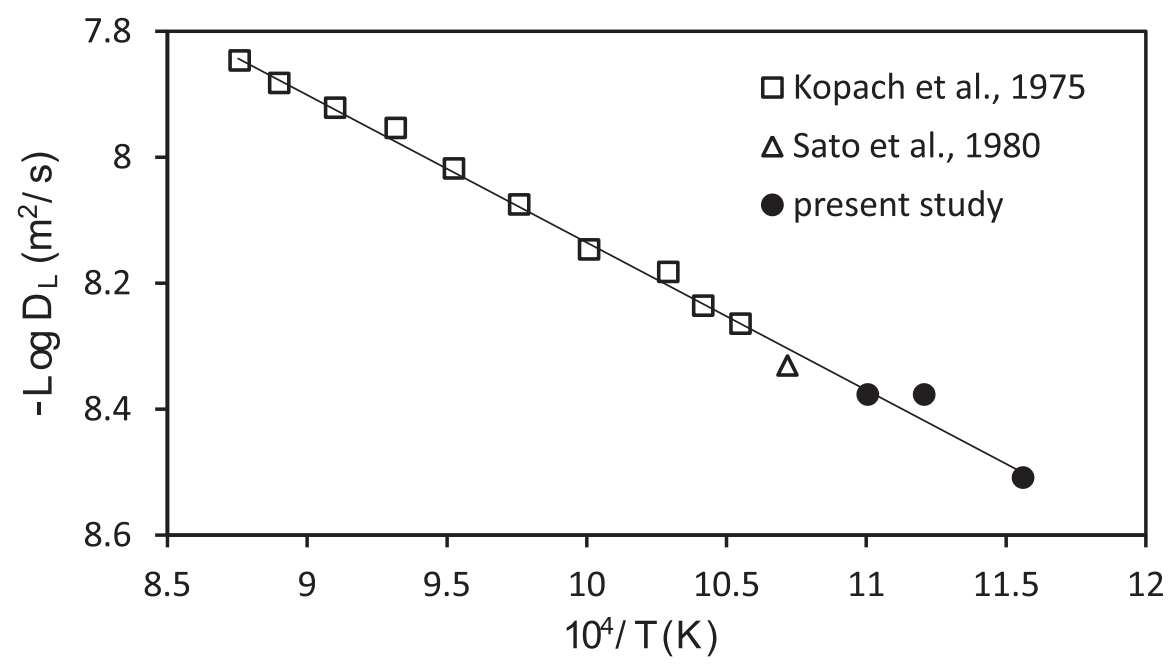

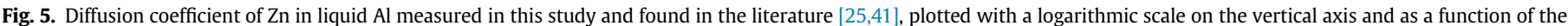
inverse of the temperature in Kelvin. The best fit of an Arrhenius law on all these data is shown with a solid line.

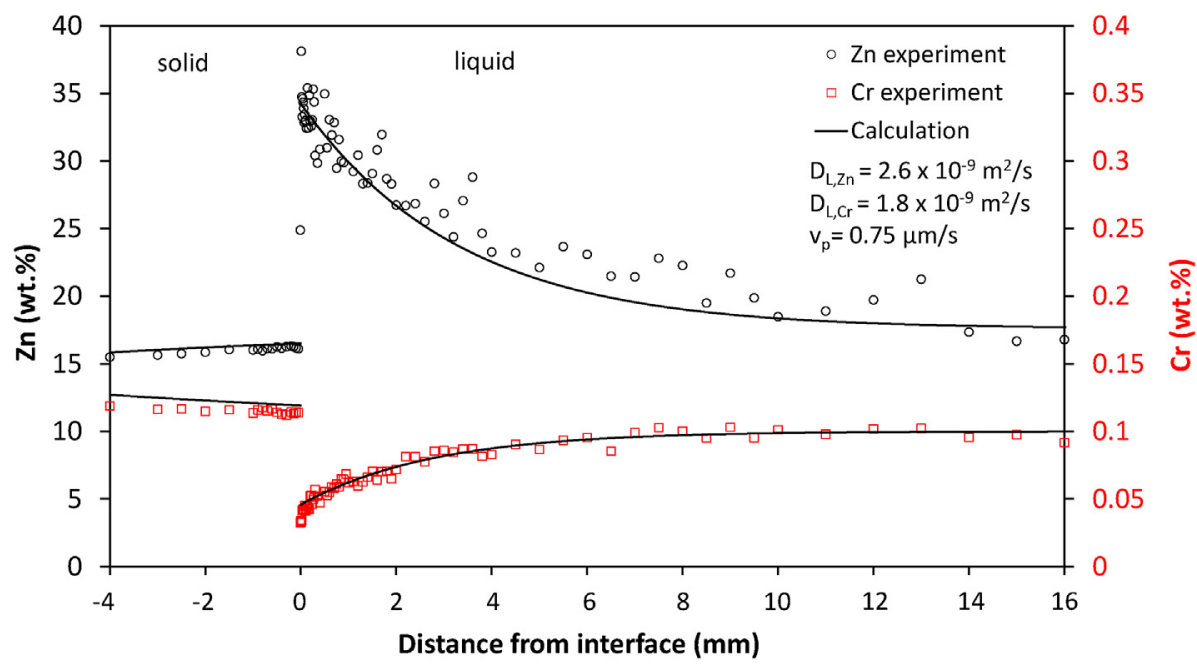

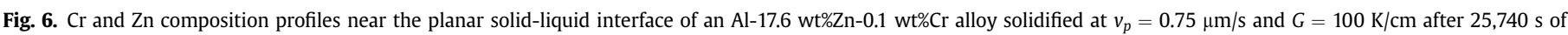
processing. The experimental solute profiles are compared with the results of the numerical calculation with the diffusion coefficients listed in Table 1. 

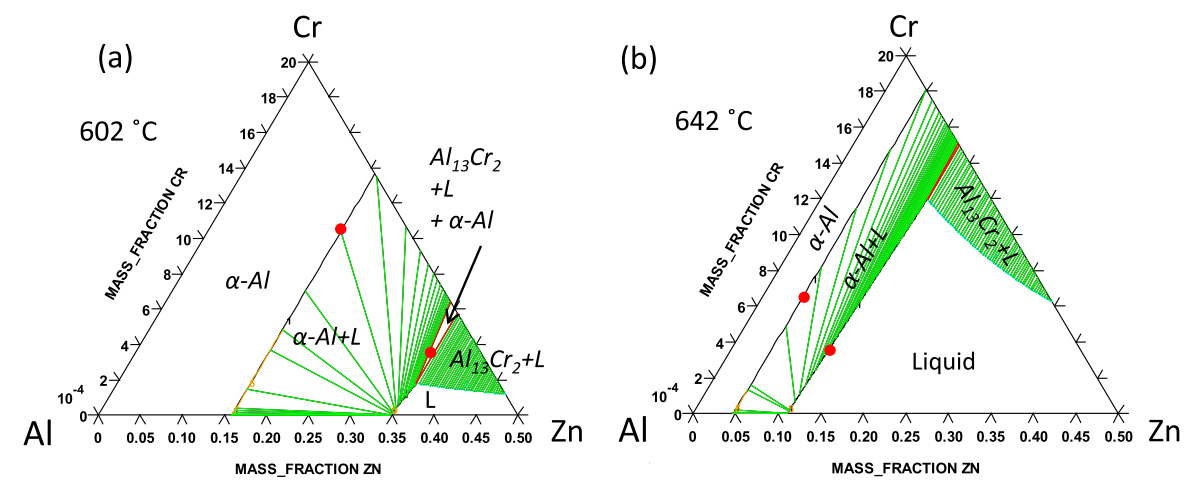

Fig. 7. Calculated isothermal sections of the Al-Zn-Cr phase diagram at (a) $602{ }^{\circ} \mathrm{C}$ and (b) $642^{\circ} \mathrm{C}$. The two red points show the compositions in the solid and liquid at the interface of the Al-17.6 wt\%Zn-0.1 wt\%Cr and Al-5.1 wt\%Zn-0.065 wt\%Cr alloys in (a) and (b), respectively. (For interpretation of the references to colour in this figure legend, the reader is referred to the web version of this article.)

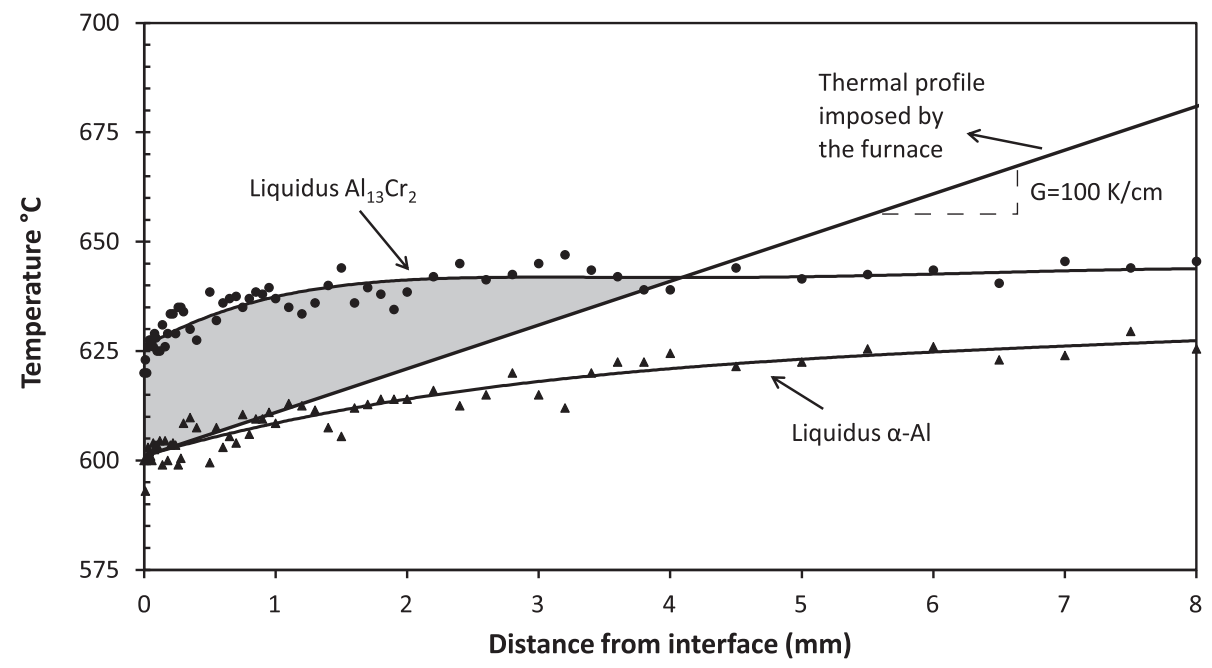

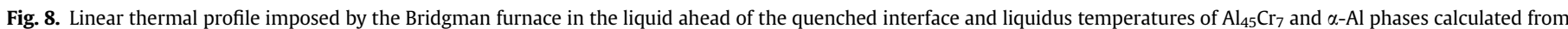
the measured $\mathrm{Cr}$ and $\mathrm{Zn}$ compositions in the liquid (Fig. 6). The gray-shaded area shows the undercooled zone in the liquid for the formation of $\mathrm{Al}_{45} \mathrm{Cr}_{7}$.

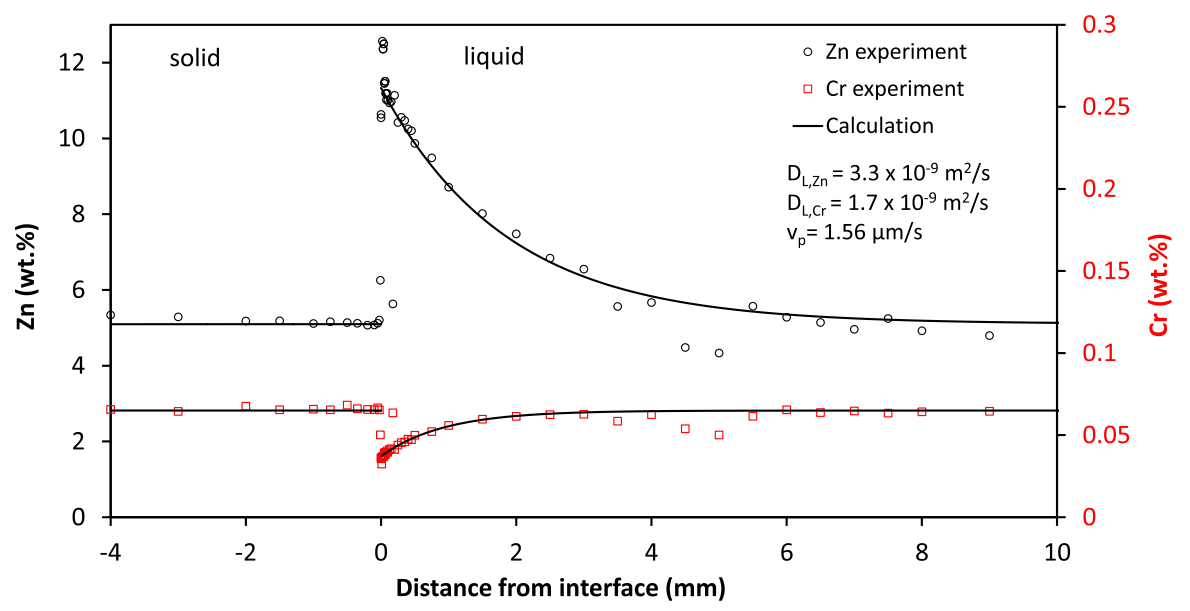

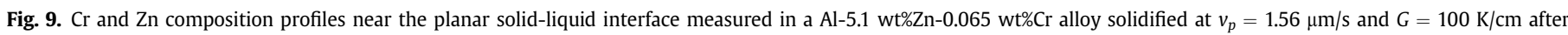
$26,400 \mathrm{~s}$ of processing. The experimental solute profiles are compared with the results of the numerical calculation with the diffusion coefficients listed in Table 1.

alloy, the tie line deduced from the interfacial compositions, and thus the partition coefficients listed in Table 1, does not agree with the phase diagram calculated with ThermoCalc.

\section{Discussion}

The method of planar front solidification to deduce the diffusion 
coefficient of solute elements in the liquid has often been used in past literature. It is known that significant errors can be present if any fluid flow is present in the system. In Al-Zn alloys in which the density gradient in the liquid is parallel to gravity, the effect of convection could be minimized by using $1.2 \mathrm{~mm}$ inner diameter capillary tubes. While shrinkage-induced convection cannot be avoided and changes direction as the $\mathrm{Zn}$ composition is increased, a nearly diffusion-controlled regime has been obtained with no visible effect of macrosegregation. The parameters that were used in the transient or steady-state regimes of planar front growth as well as the deduced values of $D_{\ell}$ and $k$ obtained from the solute profiles in the liquid for $\mathrm{Al}-\mathrm{Cr}, \mathrm{Al}-\mathrm{Zn}$ and $\mathrm{Al}-\mathrm{Zn}-\mathrm{Cr}$ alloys are summarized in Table 1. In order to compare the deduced diffusion coefficients for different alloy compositions and the values in the literature, the temperature of the solid-liquid interface, $T^{*}$, has been determined from the binary or ternary phase diagrams.

Fig. 10 summarizes the results and shows the influence of $\mathrm{Cr}$ additions on the solute diffusion coefficients in $\mathrm{Al}-\mathrm{Zn}-\mathrm{Cr}$ alloys. In order to better see the temperature dependence of the diffusion coefficient of $\mathrm{Zn}$ in liquid $\mathrm{Al}$, the values reported in the literature are also shown in this figure. Diffusion of $\mathrm{Zn}$ in the liquid of $\mathrm{Al}-\mathrm{Zn}-\mathrm{Cr}$ alloys is clearly slowed down by small $\mathrm{Cr}$ additions as compared with binary $\mathrm{Al}-\mathrm{Zn}$ alloys. Before concluding that this effect is associated with icosahedral short range order (ISRO) promoted by $\mathrm{Cr}$ addition, one should first check that this is not due to cross diffusion.

In the diffusion calculations made so far in this study for Al-Zn$\mathrm{Cr}$, it has been assumed that the two solute elements do not interact. In other words, the diffusion coefficient of $\mathrm{Zn}$ in this ternary system, i.e., $D_{\ell, Z n}^{\prime}$, has been deduced by taking into account only the composition gradient of $\mathrm{Zn}$ in the liquid. Considering now that the chemical potential of $\mathrm{Zn}, \mu_{Z n}\left(C_{\ell}(Z n), C_{\ell}(C r)\right)$, is a function of both the $\mathrm{Zn}$ and $\mathrm{Cr}$ compositions, it is shown in the Appendix that the diffusion coefficient $D_{\ell, Z n}^{\prime}$ is given by:

$D_{\ell, Z n}^{\prime}=D_{\ell, Z n}\left\{1+\left(\frac{\frac{\partial \mu_{Z n}}{\partial C_{\ell, \mathrm{r}}}}{\frac{\partial \mu_{Z n}}{\partial C_{\ell, Z n}}}\right)\left(\frac{\frac{d C_{\ell, C r}}{d z}}{\frac{d C_{\ell, Z n}}{d z}}\right)\right\}$

providing the mobility of $\mathrm{Zn}$ atoms remains unchanged when a small amount of $\mathrm{Cr}$ is added to the binary Al-Zn alloy.

The derivative of $\mu_{Z n}\left(C_{\ell}(Z n), C_{\ell}(C r)\right)$ with respect to variations of $\mathrm{Cr}$ and $\mathrm{Zn}$ compositions have been calculated using Thermocalc. They were found to be both positive and their ratio, i.e.

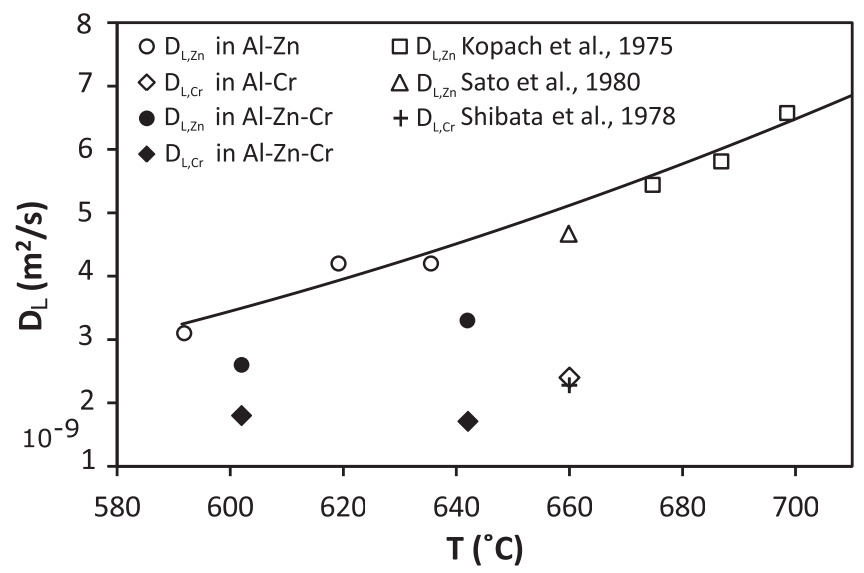

Fig. 10. Diffusion coefficient of $\mathrm{Cr}$ and $\mathrm{Zn}$ in liquid $\mathrm{Al}-\mathrm{Zn}, \mathrm{Al}-\mathrm{Cr}$ and $\mathrm{Al}-\mathrm{Zn}-\mathrm{Cr}$ alloys measured in this study and found in the literature $[41,25,28]$. The fitted Arrhenius correlation for binary Al-Zn alloys is also drawn.

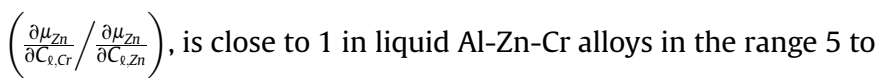
$40 \mathrm{wt} \% \mathrm{Zn}, 0.03$ to $0.1 \mathrm{wt} \% \mathrm{Cr}$ and $600-700{ }^{\circ} \mathrm{C}$. The composition gradients of $\mathrm{Cr}$ and $\mathrm{Zn}$ (i.e., $d C_{\ell, \mathrm{Cr}} / d z$ and $d C_{\ell, \mathrm{Cr}} / d z$ ) can be deduced from the measured composition profiles in the liquid ahead of the solid-liquid interface. Because $\mathrm{Zn}$ is rejected into the liquid, while $\mathrm{Cr}$ is depleted, during solidification, their ratio is always negative and this could thus contribute to slow down diffusion $\mathrm{Zn}$ in the ternary alloy. However, the ratio of composition gradients, i.e., $\left(\frac{d C_{\ell, C r}}{d z} / \frac{d C_{\ell, Z n}}{d z}\right)$, is about -0.01 only. Therefore, this is insufficient to explain the lower diffusion coefficient of $\mathrm{Zn}$ in the ternary $\mathrm{Al}-\mathrm{Zn}-\mathrm{Cr}$ alloys, and it can be logically concluded that the mobility of $\mathrm{Zn}$ atoms is decreased by $\mathrm{Cr}$ additions. Such finding seems to confirm that $\mathrm{Cr}$ induces ISRO in the liquid of Al-Zn alloys.

As mentioned in Section 1, ISRO is generally considered as a basic structural unit for most metallic liquids [2,7,8,44], providing the atomic radii of elements, alloy composition and electronic contributions meet certain criteria for interatomic interactions [45]. ISRO especially prevails in liquid $\mathrm{Al}$ alloys that form iQC phase, e.g., Al-Pd-Mn [46], Al-Mn-Cr [6], $\mathrm{Al}_{60} \mathrm{Cu}_{34} \mathrm{Fe}_{6}$ [47], decagonal QC phase, e.g., $\mathrm{Al}_{65} \mathrm{Cu}_{25} \mathrm{Co}_{10}$ [48] and $\mathrm{Al}_{74} \mathrm{Co}_{26}$ [49] and complex polytetrahedral phase, e.g., $\mathrm{Al}_{13}(\mathrm{Co}, \mathrm{Fe})_{4}$ [49], as directly evidenced by neutron scattering studies. In an alloy system such as $\mathrm{Al}-\mathrm{Cr}$, the existence in the equilibrium phase diagram of intermetallic phases with a complex crystalline structure containing several icosahedral building blocks in their large unit cell is already a strong indication that ISRO of atoms is present in the liquid [12]. As can be seen in Fig. 7, $\mathrm{Al}_{13} \mathrm{Cr}_{2}$ intermetallic phase can form in liquid $\mathrm{Al}-\mathrm{Zn}-\mathrm{Cr}$. This intermetallic phase has a monoclinic structure, with a very large unit cell containing $14 \mathrm{Cr}$ and $90 \mathrm{Al}$ atoms [16,17]. Several icosahedral building blocks formed by a $\mathrm{Cr}$ atom at the center of twelve $\mathrm{Al}$ atoms ( $\mathrm{Al}$ or $\mathrm{Zn})$ at the vertices can be seen in Fig. 11 of Ref. [14]. These icosahedral building blocks are linked together by sharing a vertex, an edge or a face, or by interlocking. $\mathrm{Al}$ and $\mathrm{Cr}$ have the appropriate atomic radii to be arranged in the icosahedral configuration and besides $\mathrm{Al}_{45} \mathrm{Cr}_{7}$, other $\mathrm{Al}$ rich intermetallic compounds formed by peritectic reactions, $\mathrm{Al}_{11} \mathrm{Cr}_{2}$ and $\mathrm{Al}_{4} \mathrm{Cr}$, have also icosahedral atomic arrangements in their unit cell [50]. Another intermetallic phase, $\mathrm{Zn}_{13}\left(\mathrm{Cr}_{x} \mathrm{Al}_{1-x}\right)_{27}(\mathrm{x}=0.34-0.37)$, has recently been shown to exhibit icosahedral building blocks in its rhombohedral system [51]. These crystallographic observations strongly support the interpretation of grain refinement induced by $\mathrm{Cr}$ during equiaxed solidification of $\mathrm{Al}-\mathrm{Zn}-\mathrm{Cr}$ alloys in terms of quasicrystalmediated nucleation [14]. The present measurements of the influence of $\mathrm{Cr}$ on the diffusion coefficient of $\mathrm{Zn}$ in $\mathrm{Al}-\mathrm{Zn}-\mathrm{Cr}$ alloys is another experimental fact that supports the formation of ISRO in this liquid alloy.

\section{Conclusion}

The quasicrystal-enhanced nucleation mechanism discovered recently in $\mathrm{Al}-\mathrm{Zn}-\mathrm{Cr}$ alloys [14] assumes that $\mathrm{Cr}$ promotes the formation of ISRO in the liquid. If such interpretation is correct, $\mathrm{Cr}$ should also influence diffusion in the liquid as a result of shortrange covalent-type interactions. In the present contribution, the diffusion coefficient of solute elements in $\mathrm{Al}-\mathrm{Cr}$, Al-Zn and $\mathrm{Al}-\mathrm{Zn}-\mathrm{Cr}$ liquid alloys have been measured by analyzing the concentration profile ahead of a planar solid-liquid interface during directional solidification after quenching. The diffusion coefficient of $\mathrm{Zn}$ in liquid $\mathrm{Al}-\mathrm{Zn}-\mathrm{Cr}$ alloy is found to be significantly smaller than that in binary $\mathrm{Al}-\mathrm{Zn}$ alloy. The decrease in diffusion coefficient of $\mathrm{Zn}$ in $\mathrm{Al}-$ $\mathrm{Zn}-\mathrm{Cr}$ alloy has been attributed to the formation of ISRO promoted by $\mathrm{Cr}$ addition. 


\section{Acknowledgements}

The authors would like to thank to Dr. Peter Jessner for his EPMA measurements and Constellium CRV, Voreppe, France, for its financial support. They also thank the staff of the Interdisciplinary Centre for Electron Microscopy (CIME) of the École Polytechnique Fédérale de Lausanne (EPFL).

\section{Appendix}

For a steady state planar growth of a binary Al-Zn alloy, the solute flux in the liquid ahead of the interface $J_{Z n}$ can be described by Fick's first law:

$J_{Z n}=-D_{Z n Z n}^{A l} \frac{\partial C_{\ell, Z n}}{\partial Z}$

$D_{Z n Z n}^{A l}$ is the diffusion coefficient of $\mathrm{Zn}$ in $\mathrm{Al}$ and given as $D_{\ell, Z n}$ in the text.

In ternary $\mathrm{Al}-\mathrm{Zn}-\mathrm{Cr}$ system, $\mathrm{Zn}$ flux is given by:

$J_{Z n}=-D_{Z n Z n}^{A l} \frac{\partial C_{\ell, Z n}}{\partial z}-D_{Z n C r}^{A l} \frac{\partial C_{\ell, C r}}{\partial z}$

where $D_{Z n C r}^{A l}$ is the cross diffusion coefficient between solute elements.

We can also write solute flux as driven by chemical potential gradient:

$J_{Z n}=-M_{Z n} x_{Z n} \frac{\partial \mu_{Z n}}{\partial z}$

where $x_{Z n}$ is the mole fraction of $Z n$ and $M_{Z n}$ is the mobility of $Z n$ in liquid. $\mu_{Z n}$ is a function of solute compositions and by means of chain rule of derivation, Equation (10) can be written as:

$J_{Z n}=-M_{Z n} x_{Z n}\left\{\frac{\partial \mu_{Z n}}{\partial C_{\ell, Z n}} \frac{\partial C_{\ell, Z n}}{\partial z}+\frac{\partial \mu_{Z n}}{\partial C_{\ell, C r}} \frac{\partial C_{\ell, C r}}{\partial z}\right\}$

By the definition of diffusion coefficients, i.e., $D_{Z n Z n}^{A l}=M_{Z n} x_{Z n} \frac{\partial \mu_{Z n}}{\partial C_{\ell, Z n}}$ and $D_{Z n C r}^{A l}=M_{Z n} x_{Z n} \frac{\partial \mu_{Z n}}{\partial C_{\ell, C r}}$, Equations (10) and (12) are the same.

If we deduce liquid diffusion coefficient of $\mathrm{Zn}$ in measurements by neglecting cross diffusion between $\mathrm{Zn}$ and $\mathrm{Cr}$, i.e. $D_{\ell . \mathrm{Zn}}^{\prime}$, the flux can be written as:

$J_{Z n}=-D_{\ell, Z n}^{\prime} \frac{\partial C_{\ell, Z n}}{\partial Z}$

By using diffusion coefficient definitions, Equations (10) and (13), we can write:

$D_{\ell, Z n}^{\prime}=D_{Z n Z n}^{A l}\left\{1+\left(\frac{\frac{\partial \mu_{Z n}}{\partial C_{\ell, C r}}}{\frac{\partial \mu_{Z n}}{\partial C_{\ell, Z n}}}\right)\left(\frac{\frac{d C_{\ell, C r}}{d z}}{\frac{d C_{\ell, Z n}}{d z}}\right)\right\}$

\section{References}

[1] J.O. Andersson, L. Höglund, B. Jönsson, J. Ågren, G.R. Purdy, Fundamentals and Applications of Ternary Diffusion, Pergamon Press, New York, 1990, p. 153.

[2] F.C. Frank, Supercooling of liquids, Proc. R. Soc. Lond. A. Math. Phys. Sci. 215 (1952) 43-46.

[3] P.J. Steinhardt, D.R. Nelson, M. Ronchetti, Bond-orientational order in liquids and glasses, Phys. Rev. B 28 (1983) 784.

[4] X.W. Fang, C.Z. Wang, Y.X. Yao, Z.J. Ding, K.M. Ho, Competition between fcc and icosahedral short-range orders in pure and samarium-doped liquid aluminum from first principles, Phys. Rev. B 83 (2011) 224203.

[5] H. Reichert, O. Klein, H. Dosch, M. Denk, V. Honkimki, T. Lippmann, et al.,
Observation of five-fold local symmetry in liquid lead, Nature 408 (2000) 839-841.

[6] V. Simonet, F. Hippert, M. Audier, R. Bellissent, Local order in liquids forming quasicrystals and approximant phases, Phys. Rev. B 65 (2001) 24203.

[7] T. Schenk, D. Holland-Moritz, V. Simonet, R. Bellissent, D.M. Herlach, Icosahedral short-range order in deeply undercooled metallic melts, Phys. Rev. Lett. 89 (2002) 75507.

[8] D. Holland-Moritz, T. Schenk, R. Bellissent, V. Simonet, K. Funakoshi, J.M. Merino, et al., Short-range order in undercooled Co melts, J. Non. Cryst. Solids 312 (2002) 47-51.

[9] D. Shechtman, I. Blech, D. Gratias, J.W. Cahn, Metallic phase with long-range orientational order and no translational symmetry, Phys. Rev. Lett. 53 (1984) 1951-1953.

[10] K.F. Kelton, Quasicrystals: Structure and stability, Int. Mater. Rev. 38 (1993) $105-137$.

[11] E. Huttunen-Saarivirta, Microstructure, fabrication and properties of quasicrystalline Al-Cu-Fe alloys: A review, J. Alloys Compd 363 (2004) 154-178.

[12] F.C. Frank, J.S. Kasper, Complex alloy structures regarded as sphere packings. I. Definitions and basic principles, Acta Crystallogr. 11 (1958) 184-190.

[13] V. Elser, C.L. Henley, Crystal and quasicrystal structures in Al-Mn-Si alloys, Phys. Rev. Lett. 55 (1985) 2883-2886.

[14] G. Kurtuldu, P. Jarry, M. Rappaz, Influence of $\mathrm{Cr}$ on the nucleation of primary $\mathrm{Al}$ and formation of twinned dendrites in Al-Zn-Cr alloys: Can icosahedra solid clusters play a role? Acta Mater. 61 (2013) 7098-7108.

[15] M. Rappaz, G. Kurtuldu, Thermodynamic aspects of homogeneous nucleation enhanced by icosahedral short range order in liquid fcc-type alloys, JOM (2015) 1-9.

[16] M.J. Cooper, The structure of the intermetallic phase ( $\mathrm{Cr}-\mathrm{Al})$, Acta Crystallogr 13 (1960) 257-263.

[17] Z.B. He, B.S. Zou, K.H. Kuo, The monoclinic $\mathrm{Al}_{45} \mathrm{Cr}_{7}$ revisited, J. Alloys Compd. 417 (2006) L4-L8.

[18] G. Kurtuldu, M. Rappaz, Probability of twin boundary formation associated with the nucleation of equiaxed grains on icosahedral quasicrystal templates, in: IOP Conf. Ser. Mater. Sci. Eng, 2015, p. 12012.

[19] G. Kurtuldu, A. Sicco, M. Rappaz, Icosahedral quasicrystal-enhanced nucleation of the fcc phase in liquid gold alloys, Acta Mater 70 (2014) 240-248.

[20] W. Hornfeck, R. Kobold, M. Kolbe, D. Herlach, Quasicrystal Nucleation in an Intermetallic glass-former, arXiv preprint arXiv:1410.2952, 2014.

[21] S.M. Chathoth, A. Meyer, M.M. Koza, F. Juranyi, Atomic diffusion in liquid Ni, NiP, PdNiP, and PdNiCuP alloys, Appl. Phys. Lett 85 (21) (2004) 4881-4883.

[22] A. Meyer S. Stber, D. Holland-Moritz, O. Heinen, T. Unruh, Determination of self-diffusion coefficients by quasielastic neutron scattering measurements of levitated Ni droplets, Phys. Rev. B 77 (2008) 092201.

[23] A. Meyer, Self-diffusion in liquid copper as seen by quasielastic neutron scattering, Phys. Rev. B 81 (2010) 012102.

[24] J. Horbach, S.K. Das, A. Griesche, M.-P. Macht, G. Frohberg, A. Meyer, Selfdiffusion and interdiffusion in Al80Ni20 melts: Simulation and experiment, Phys. Rev. B 75 (2007) 174304.

[25] T. Sato, K. Ito, G. Ohira, Interfacial stability of planar solid-liquid interface during unidirectional solidification of Al-Zn alloy, Trans. Jpn. Inst. Met. 21 (1980) 441-448.

[26] R.M. Sharp, A. Hellawell, The microscopy and composition of quenched solidliquid interfaces, J. Cryst. Growth 5 (1969) 155-161.

[27] K. Shibata, T. Sato, G. Ohira, The solute distributions in dilute Al-Ti alloys during unidirectional solidification, J. Cryst. Growth 44 (1978) 435-445.

[28] K. Shibata, T. Sato, G. Ohiro, Morphological stabilities of planar solid-liquid interfaces during unidirectional solidification of dilute $\mathrm{Al}-\mathrm{Ti}$ and $\mathrm{Al}-\mathrm{Cr}$ alloys, J. Cryst. Growth 44 (1978) 419-434.

[29] J.-H. Lee, S. Liu, H. Miyahara, R. Trivedi, Diffusion-coefficient measurements in liquid metallic alloys, Metall. Mater. Trans. B 35 (2004) 909-917.

[30] D. Froschhammer, H.M. Tensi, H. Zoller, U. Feurer, Diffusion in the liquid near the moving solid-liquid interface of an Aluminum-0.3 pct Copper alloy, Metall. Mater. Trans. B 11 (1980) 169-171.

[31] T. Sato, G. Ohira, Stability of a planar solid-liquid interface during unidirectional solidification of Al-0.1 wt\% Cu alloy, J. Cryst. Growth 40 (1977) 78-89.

[32] F. Kohler, L. Germond, J.-D. Wagniére, M. Rappaz, Peritectic solidification of $\mathrm{Cu}-\mathrm{Sn}$ alloys: Microstructural competition at low speed, Acta Mater 57 (2009) $56-68$.

[33] G. Kurtuldu, P. Jessner, M. Rappaz, Peritectic reaction on the Al-rich side of AlCr system, J. Alloys Compd. 621 (2015) 283-286.

[34] J.A. Dantzig, M. Rappaz, Solidification, EPFL Press, 2009. http://solidification. org/.

[35] J.L. Murray, The Al-Cr (Aluminum-Chromium) system, J. Phase Equilib. 19 (1998) 367-375.

[36] N.A. El-Mahallawy, M.M. Farag, Effect of some thermal parameters on the directional solidification process, J. Cryst. Growth 44 (1978) 251-258.

[37] S. Liu, P. Mazumder, R. Trivedi, A new thermal assembly design for the directional solidification of transparent alloys, J. Cryst. Growth 240 (2002) $560-568$.

[38] V.G. Smith, W.A. Tiller, J. Rutter, A mathematical analysis of solute redistribution during solidification, Can. J. Phys. 33 (1955) 723-745.

[39] J. Valloton, Phase Competition in Peritectic Cu-Sn Alloys during Solidification at Low Speed in a Diffusive Regime, Ecole Polytechnique Fédérale de Lausanne, 2012.

[40] J.L. Murray, The Al-Zn (Aluminum-Zinc) system, Bull. Alloy Phase Diag. 4 
(1983) 55-73.

41] I.I. Kopach, E.E. Lukashenko, V.N. Efimov, Y.N. Rekhlov, Diffusion of lead and zinc in liquid aluminum, Izv. Vyss. Uchab. Zaved. Tsvet. Met. (1975) 49-52.

[42] Y. Du, Y.A. Chang, B. Huang, W. Gong, Z. Jin, H. Xu, et al., Diffusion coefficients of some solutes in fcc and liquid Al: Critical evaluation and correlation, Mater. Sci. Eng. A 363 (2003) 140-151.

[43] G. Kurtuldu, Influence of Trace Elements on the Nucleation and Solidification Morphologies of Fcc Alloys and Relationship with Icosahedral Quasicrysta Formation, École Polytechnique Fédérale de Lausanne, 2014.

[44] D. Holland-Moritz, O. Heinen, R. Bellissent, T. Schenk, Short-range order of stable and undercooled liquid titanium, Mater. Sci. Eng. A 449 (2007) 42-45.

[45] D.M. Herlach, D.M. Matson, Solidification of Containerless Undercooled Melts Wiley-VCH, 2012

[46] V. Simonet, F. Hippert, H. Klein, M. Audier, R. Bellissent, H. Fischer A.P. Murani, D. Boursier, Local order and magnetism in liquid Al-Pd-Mn alloys,
Phys. Rev. B 58 (1998) 6273-6286.

[47] D. Holland-Moritz, T. Schenk, V. Simonet, R. Bellissent, Short-range order in undercooled and stable melts forming quasicrystals and approximants and its influence on nucleation, Philos. Mag. 86 (2006) 255-262.

[48] D. Holland-Moritz, T. Schenk, V. Simonet, R. Bellissent, P. Convert, T. Hansen, D.M. Herlach, Short-range order in undercooled metallic liquids, Mater. Sci. Eng. A 375 (2004) 98-103.

[49] D. Holland-Moritz, T. Schenk, V. Simonet, R. Bellissent, P. Convert, T. Hansen, Short-range order in undercooled melts forming quasicrystals and approximants, J. Alloys Compd. 342 (2002) 77-81.

[50] M. Audier, M. Durand-Charre, E. Laclau, H. Klein, Phase equilibria in the Al-Cr system, J. Alloys Compd. 220 (1995) 225-230.

[51] S. Thimmaiah, M.-K. Han, G.J. Miller, $\mathrm{Zn}_{13}\left(\mathrm{Cr}_{x} \mathrm{Al}_{1-x}\right)_{27}(x=0.34-0.37)$ : A new intermetallic phase containing icosahedra as building units, Z. Für Krist. 226 (2011) 557-567. 